acceptability of psychological explanations of delusional misidentification (Anderson \& Williams, 1994). Authors proposing psychological pathogeneses accept it is difficult to explain object misidentification by psychological mechanisms (Epoch, 1986) and the assertion that it is simply an extension of duplicated people (Colman, 1933) is immediately falsified by substitution of inanimate objects without person duplication.

'Delusional gross replacement of inanimate objects syndrome' is neither an accurate nor appealing description for a phenomenon which appears to be a variant of the Capgras' phenomenon and which may, for the time being, be most conveniently and simply referred to as the delusion of inanimate doubles.

ANDERson, D. N. (1988) The delusion of inanimate doubles: implications for understanding the Capgras' phenomenon. British Journal of Psychiatry, 153, 694-699.

- (1990) Understanding Capgras' syndrome. British Journal of Psychiatry, 157, 622-623.

\& Wrulams, E. (1994) The delusion of inanimate doubles. Psychopathology (in press).

Colman, S. M. (1993) Misidentification and non-recognition. Journal of Mental Science, 79, 42-51.

ENoch, M. D. (1986) Whose double? In The Delusional Misidentification Syndromes (ed. G.N. Christodoulou), pp. 22-29. Basel: Karger.

D.N. ANDERSON E. Williams

Sir Douglas Crawford Unit

Mossley Hill Hospital

Liverpool L18 8BU

\section{Unipolar mania in non-Western cultures}

SIR: The plea of Shulman \& Tohen (BJP, April $1994,164,547-549)$ for resurrecting the concept of unipolar mania is particularly germane from a cross-cultural perspective.

In 1904, Emil Kraepelin visited several nonWestern societies as part of an international lecture tour. During the course of his stay in Indonesia, he noted that there appeared to be an absence of depressive disorders - a fact that he attributed to diet and climate. Today, unipolar mania is still common in many non-Western cultures. In Nigeria, for example, recurrent mania without depression was noted to be "the rule rather than the exception" (Makanjuola, 1982). Of 50 Chinese patients attending the first lithium clinic in Hong Kong, 18 manifested only manic episodes during their affective relapses (Lee, 1992). A higher prevalence of mania than depression was also found in China and other non-Western cultures such as Africa, Indonesia, and the Caribbean (Singer, 1975). In CCMD-2 (Chinese Classification of Mental Disorders, 2nd edition), the official nostologic system widely used in China (Young, 1989, p. 533), a category (code 31) of 'manic disorder' which requires the absence of previous depressive episodes can be found. Not uncommonly, my medical students asked me why Chinese patients with multiple episodes of mania should be regarded as 'bipolar' according to Western nosology.

Although systemic data are lacking, the possibility certainly exists that unipolar manic patients may exhibit particular neuroradiological, polysomnographic or other biological correlates, and a different clinical course, as well as treatment experience and response. In Hong Kong, limited evidence suggested that while thyroid autoimmunity occurred in a proportion of manic-depressive patients, they were absent in patients with unipolar mania. This may support the view that depression, not mania, has an adverse effect on cellular immunity (Lee et al, 1992). It is unclear whether the absence of depressive episodes would reduce suicide in this subgroup of 'bipolar' patients, but in eastern India, unipolar mania is associated with significantly increased affective morbidity (Khanna et al, 1992).

Major epidemiological surveys using standardised Western instruments have not made a distinction between unipolar mania and bipolar disorder. Given that the non-Western cultures make up $80 \%$ of the world but are poorly prepared to publish in the English literature, more attention to unipolar mania is clearly in order.

Khanna, R., Gupta, N. \& Shanker, S. (1992) Course of bipolar disorder in eastern India. Journal of Affective Disorders, 24, $35-41$.

LEE, S. (1992) The first lithium clinic in Hong Kong - a Chinese profile. Australian and New Zealand Journal of Psychiatry, 26, $450-453$.

Chow, C. C., WrNG, Y. K., et al (1992) Thyroid abnormalities during chronic lithium treatment in Hong Kong Chinese-a controlled study. Journal of Affective Disorders, 26, 173-178.

Makanjuola, R. O. A. (1982) Manic disorder in Nigerians. British Journal of Psychiatry, 141, 459-463.

SINGER, K. (1975) Depressive disorders from a transcultural perspective. Social Science and Medicine, 9, 289-301.

Young, D. (1989) Chinese Diagnostic Criteria and Case Examples of Mental Disorders. Hunan University Press: Hunan (in Chinese).

SING LeE

Department of Psychiatry

HONG YU

Prince of Wales Hospital

Shatin

Hong Kong 